\title{
Estudos experimentais com plantas cianogênicas em bovinos ${ }^{1}$
}

\author{
Carlos Hubinger Tokarnia ${ }^{2}$, Paulo Vargas Peixoto², Marilene F. Brito ${ }^{3}$, Marcos D. \\ Duarte $^{4}$ e Luis A.C. Brust ${ }^{5}$
}

\begin{abstract}
Tokarnia C.H., Peixoto P.V, Brito M.F., Duarte M.D. \& Brust L.A.C. 1999. [Experimental studies in cattle with cyanogenic plants.] Estudos experimentais em bovinos com plantas cianogênicas. Pesquisa Veterinária Brasileira 19(2):84-90. Projeto Sanidade Animal Embrapa/UFRRJ, Km 47, Seropédica, RJ 23851-970, Brazil.

These studies were performed in order to obtain additional data on Brazilian cyanogenic plants. Three animals, severely poisoned by Piptadenia macrocarpa (=Anadenanthera macrocarpa), recovered readily when treated intravenously with $660 \mathrm{mg} / \mathrm{kg}$ of sodium hyposulphite (sodium thiosulphate) plus $30 \mathrm{~g}$ dissolved in water given by stomach tube. Fresh leaves (in the sprouting phase), fed in October, were more poisonous than mature leaves fed in March. Dried leaves slowly lost their toxicity within a few months. Both the fresh and dried leaves of Piptadenia viridiflora showed similar toxic effects to $P$. macrocarpa. As this was also readily reversed by the administration of sodium hyposulphite in two animals, $P$. viridiflora can be included in the group of toxic cyanogenic plants. Four animals severely poisoned by the leaves of Holocalyx glaziovii (=Holocalyx balansae) also recovered readily after receiving sodium hyposulphite. The dried leaves of $H$. glaziovii also slowly lost their toxicity within a few months. Two animals severely poisoned by the leaves of Manihot glaziovii also recovered readily with sodium hyposulphite. However, dried leaves were no longer poisonous. The leaves of $H$. glaziovii and of M. glaziovii always gave a quick (in less than 5 minutes) positive reaction to the picrate test for cyanide. Those of P. macrocarpa and P. viridiflora reacted more slowly (after 15 and 10 to 30 minutes respectively) when in the sprouting stage, and even slower when the leaves were mature. The slower reactions seen with Piptadenia spp indicate a slower breakdown of the hidrocyanic glycosides and this also explains the longer course of poisoning seen in cattle fed these species. The dried leaves of Piptadenia spp and also of $H$. glaziovii gave slower reactions than the fresh leaves. These data permit the conclusion that the picrate test for cyanide is of relative value when evaluating the amount of cyanogenic glycosides in plants.
\end{abstract}

INDEX TERMS: Poisonous plants, hydrocyanic poisoning, Piptadenia macrocarpa, Anadenanthera macrocarpa, Piptadenia viridiflora, Holocalyx glaziovii, Manihot glaziovii, cattle.

RESUMO.- O presente estudo experimental foi realizado com a finalidade de preencher lacunas no conhecimento sobre algumas plantas cianogênicas no Brasil. Observou-se que três bovinos gravemente intoxicados por Piptadenia macrocarpa

\footnotetext{
${ }^{1}$ Aceito para publicação em 10 de novembro de 1998.

${ }^{2}$ Depto Nutrição Animal e Pastagem, Universidade Federal Rural do Rio de Janeiro (UFRRJ), Km 47, Seropédica, RJ 23851-970; bolsistas do CNPq (305010/76-VT e 302342/86-9). UFRRJ.

${ }^{3}$ Depto Epidemiologia e Saúde Pública, Setor de Anatomia Patológica, UFRRJ.

${ }^{4}$ Médico-veterinário, Hospital Veterinário, Setor de Grandes Animais,

${ }^{5}$ Médico-veterinário, Residente na Clínica de Bovinos de Garanhuns, Univ. Fed. Rural de Pernambuco.
}

(=Anadenanthera macrocarpa), desenvolveram o clássico quadro de intoxicação cianídrica, mas se recuperaram de imediato quando tratados pela aplicação endovenosa de $660 \mathrm{mg} /$ $\mathrm{kg}$ de hipossulfito (tiossulfato) de sódio, associada à administração de $30 \mathrm{~g}$ da mesma substância, dissolvidos na água, por sonda esofagiana. Verificou-se ainda que as folhas dessa planta são mais tóxicas em outubro (fase de brotação) do que em março (folhas maduras) e que as folhas dessecadas perdem lentamente em toxidez, no decorrer de meses. As folhas frescas, e também a dessecadas, de Piptadenia viridiflora produziram quadro clínico-patológico muito semelhante ao observado na intoxicação por $P$. macrocarpa, também rapidamente reversível, em dois bovinos, pela administração de hipossulfito de sódio, o que permite inseri-la entre as plantas cianogênicas. Quatro bovinos gravemente intoxicados 
pelas folhas de Holocalyx glaziovii se recuperaram prontamente após a administração de hipossulfito de sódio; verificou-se que as folhas dessecadas dessa planta perdem lentamente em toxidez, no decorrer de meses. Dois bovinos gravemente intoxicados pelas folhas de Manihot glaziovii se recuperaram de imediato pelo tratamento com hiposulfito de sódio. As folhas dessecadas desta planta perderam a sua toxidez. Com Holocalyx glaziovii e Manihot glaziovii, as reações positivas pelo teste do papel picro-sódico foram sempre muito rápidas (dentro de 5 minutos), enquanto que com Piptadenia macrocarpa e Piptadenia viridiflora as reações foram mais lentas (dentro de 15 minutos e de 10 a 30 minutos respectivamente) para a brotação, e ainda mais retardadas para as folhas maduras. A reação mais lenta, observada no teste do papel picro-sódico com as folhas de Piptadenia spp, indica um desdobramento mais vagaroso do glicosídeo cianogênico e está de acordo com a evolução mais longa observada na intoxicação por essas plantas. As folhas dessecadas de Piptadenia spp e também de $H$. glaziovii forneceram reações mais lentas que as folhas frescas. Esses dados permitem concluir que o teste do papel picro-sódico tem valor apenas relativo na avaliação das concentrações de glicosídeos cianogênicos em material vegetal.

TERMOS DE INDEXAÇÃO: Plantas tóxicas, intoxicação cianídrica, Piptadenia macrocarpa, Anadenanthera macrocarpa, Piptadenia viridiflora, Holocalyx glaziovii, Holocalyx balansae, Manihot glaziovii, bovinos.

\section{INTRODUÇÃO}

Estudos realizados no Brasil permitiram enquadrar Piptadenia macrocarpa (Tokarnia et al. 1994), Holocalyx glaziovii (Armién et al. 1995) e Manihot glaziovii (Tokarnia et al. 1994) entre as plantas cianogênicas, porém alguns aspectos sobre as intoxicações por essas plantas não estavam bem definidos.

Diferentemente do observado com outras plantas cianogênicas, as folhas frescas ou dessecadas de P. macrocarpa, quando submetidas ao teste do papel picro-sódico, sempre tem apresentado reações lentas e variáveis. A evolução do quadro clínico apresentado pelos animais intoxicados por essa planta também tem-se revelado mais protraída. Em relação a $H$. glaziovii, ainda não haviam sido realizados experimentos com as folhas dessecadas

Já Piptadenia viridiflora, árvore conhecida por "espinheiro" ou "surucucu”, causaria intoxicação em bovinos, de acordo com informações de criadores do oeste da Bahia. Observamos que, realmente, os bovinos ingerem as folhas, apesar de a planta ser bem provida de espinhos. Anteriormente não tinham sido realizados quaisquer estudos sobre a toxidez dessa planta.

Animais intoxicados por plantas cianogênicas respondem prontamente à aplicação intravenosa de hipossulfito de sódio. Essa resposta imediata à medicação específica confirma que o animal ingeriu glicosídeos cianogênicos (Burrows 1981, Radostits 1994).

\section{MATERIAL E MÉTODOS}

As folhas recém-colhidas e/ou dessecadas de Piptadenia macrocarpa Benth.(=Anadenanthera macrocarpa (Benth.) Brenan),
Piptadenia viridiflora (Kunth.) Benth. e Holocalyx glaziovii Taub. (=Holocalyx balansae Micheli), árvores pertencentes à família Leguminosae Mimosoideae, e de Manihot glaziovii Muell. Arg., árvore pertencente à família Euphorbiaceae, foram administradas manualmente por via oral a bovinos. Os animais foram acompanhados clinicamente e, em caso de morte, era realizada a necropsia complementada por exames histopatológicos. As quantidades administradas das folhas dessas árvores eram determinadas pela capacidade de os animais as deglutirem, pois verificou-se que, após período variável de tempo, os animais não mais conseguiam deglutir a planta.

Vários animais intoxicados com cada uma dessas plantas, recémcolhidas e/ou dessecadas, foram submetidos ao tratamento específico preconizado para a intoxicação cianídrica: $660 \mathrm{mg}$ de hipossulfito (tiossulfato) de sódio por quilo de peso do animal, em solução aquosa a $20 \%$ por via endovenosa, associados a $30 \mathrm{~g}$ da mesma substância, por sonda esofagiana (Burrows 1981, Radostits 1989). A aplicação endovenosa da medicação era retardada ao máximo, até que o animal mostrasse acentuada sintomatologia da intoxicação, com risco de vida. Após o tratamento, o animal era considerado recuperado quando começava a comer forragem.

Amostras das folhas administradas foram submetidas ao teste do papel picro-sódico (Henrici 1926, Conn 1979). As folhas dessecadas foram previamente umedecidas com água por ocasião da realização do teste.

As folhas foram dessecadas à sombra, e guardadas em sacos de tecido de algodão, em temperatura ambiente, à sombra, até a sua utilização. Para se obter as doses correspondentes das plantas frescas recém-coletadas, as quantidades indicadas para as folhas dessecadas devem ser multiplicadas, no caso de $P$. macrocarpa, por 1,75 , no de $P$. viridiflora por 1,88 e no de $H$. glaziovii por 2,0 .

As folhas de $P$. macrocarpa e de $M$. glaziovii foram coletadas de árvores cultivadas no município de Seropédica, RJ, a partir de sementes procedentes do Piauí (mun. Pimenteiras), e de estacas procedentes do Ceará (mun. Maranguape), respectivamente. As folhas de Holocalyx glaziovii foram coletadas de árvores cultivadas no município de Itaguaí, RJ, a partir de mudas obtidas no Estado de São Paulo (mun. Campinas) e as folhas de Piptadenia viridiflora foram coletadas no município de Wanderley, BA.

$O$ trabalho experimental foi realizado nas dependências do Projeto Sanidade Animal Embrapa/UFRRJ Km 47, Seropédica, RJ, com exceção dos experimentos com as folhas frescas de $P$. viridiflora que foram executados em Wanderley, BA.

\section{RESULTADOS}

\section{Piptadenia macrocarpa}

Os animais que ingeriram essa planta evidenciaram o clássico quadro de intoxicação cianídrica (vide protocolos), prontamente reversível pela administração do tratamento específico. Detalhes desses experimentos são apresentados no Quadro 1.

Resumo dos protocolos dos experimentos com P. macrocarpa:

Bovino 5288. Em 17.03.98, às 10:22h, início da administração. Às 12:10h foi interrompida a administração; o animal mastigava as folhas salivando muito. Em seguida, o animal apresentou leves tremores musculares, taquicardia (FC $120^{6}$ ), movimentos respiratórios profundos, leve apatia. Às 17:12h começou a comer capim, recuperado.

${ }^{6} \mathrm{~T}=$ Temperatura em ${ }^{\circ} \mathrm{C} ; \mathrm{FC}=$ frequiencia cardíaca por minuto; $\mathrm{FR}=$ fequência respiratória por minuto; Ru x/x = movimentos do rúmen por minutos. 
Quadro 1. Experimentos em bovinos com as folhas de Piptadenia macrocarpa

\begin{tabular}{|c|c|c|c|c|c|c|c|c|}
\hline $\begin{array}{l}\text { Bov. } \\
\text { no. }\end{array}$ & Folhas & Data da coleta & Dose $\mathrm{g} / \mathrm{kg}$ & $\begin{array}{l}\text { Data e hora da } \\
\text { administração }\end{array}$ & $\begin{array}{c}\text { Início dos } \\
\text { sintomas } \\
\end{array}$ & $\begin{array}{c}\text { Início do } \\
\text { tratamento }\end{array}$ & $\begin{array}{l}\text { Término do } \\
\text { tratamento }\end{array}$ & Recuperação \\
\hline 5288 & Frescas & 17.03 .98 & 11,8 & 17.03.98 10:22-12:10h & $12: 10 \mathrm{~h}$ & - & - & $17: 12 \mathrm{~h}$ \\
\hline 5290 & “ & “ & 17,9 & 17.03.98 13:50-16:00h & $16: 00 h$ & - & - & 19:00h \\
\hline 5287 & “ & 16.10 .98 & 8,9 & 16.10.98 11:45-12:30h & $12: 30 h$ & $13: 09 h$ & $13: 17 \mathrm{~h}$ & $13: 43 h$ \\
\hline 5292 & “ & “ & 6,0 & $16.10 .98 \quad 17: 00-18: 10 h$ & $18: 10 h$ & $18: 22 \mathrm{~h}$ & $18: 28 \mathrm{~h}$ & $18: 34 h$ \\
\hline 5292 & Dessecadas & 28.10 .97 & $22,1^{\mathrm{a}}$ & 05.03.98 09:15-11:58h & - & - & - & - \\
\hline 5287 & “ & “ & 17,1 & 05.03.98 08:50-11:21h & - & - & - & - \\
\hline 5296 & “ & 16.10 .98 & 7,9 & 13.01.99 09:00-10:45h & $10: 45 h$ & $12: 03 h$ & $12: 13 \mathrm{~h}$ & $13: 45 h$ \\
\hline
\end{tabular}

aNos experimentos com as plantas dessecadas sempre são indicadas as doses da planta nesse estado.

Bovino 5290. Em 17.03.98, às 13:50h, início da administração. Às 16:00h foi interrompida a administração, o animal não mais mastigava, nem engolia as folhas. Em seguida, o animal apresentou leves tremores musculares, movimentos respiratórios profundos, leve apatia. Às 19:00h começou a comer capim, recuperado.

Bovino 5287. Em 16.10.98, às $11: 35 \mathrm{~h}, \mathrm{~T} 38,0^{\circ}, \mathrm{FC} 60, \mathrm{FR} \mathrm{20,Ru} \mathrm{1/2.} \mathrm{Às}$ 11:45h, início da administração. Às 12:30h o animal deitou, enquanto recebia a planta e mastigava as folhas sem engolir. Tangido, levantou-se muito desequilibrado, com tremores musculares generalizados. Foi interrompida a administração. Às 12:35h apresentou andar muito desequilibrado, com tremores, hipermetria, FR 24 com respiração forçada, FC 112. Às 12:45h estava parado, não quis andar, e logo recomeçaram os tremores musculares generalizados, às vezes muito fortes. Às $12: 51 \mathrm{~h}$, quase caindo, acabou deitandose em decúbito esternal, com o pescoço em "S", e fazendo movimentos laterais desordenados com a cabeça. Às 13:04h ficou com a cabeça encostada no flanco, respiração abdominal, sacudindo todo corpo. Às 13:09h, início e, às $13: 17 \mathrm{~h}$, término do tratamento. Às $13: 18 \mathrm{~h}$, o animal colocou a cabeça para frente, a respiração tornou-se normal, FR 16. Às 13:35h, quando tangido, levantou-se e andou normalmente. Às $13: 43 \mathrm{~h}$ estava pastando, recuperado.

Bovino 5292. Em 16.10.98, às 17:00h, T 38,70, FC 60, FR 20, Ru 1/2 . Às 17:00h, início da administração. Às 18:00h o animal mastigava, salivando muito, sem engolir. Às 18:10h, o animal caiu; tangido com energia, levantou-se, muito desequilibrado. Foi interrompida a administração. Às 18:12h caiu novamente, permanecendo em decúbito esternal, FC 140, FR 36, respiração audível à distância. Ficou deitado meio de lado, com a cabeça encostada no solo. Às 18:22h, início e às 18:28h, término do tratamento. Às 18:28h, FC 96; às 18:29h, respiração normal, cabeça erguida. Às 18:32h levantou- se, com andar desequilibrado. Às 18:34h estava pastando, sem sintomas, recuperado.

Bovino 5296. Em 13.1.99, às 9:00h, T 38,5o, FC 60, FR 20, Ru 3/2. Às 9:00h, início da administração. Às 10:45, o animal não mais deglutia as folhas. Foi interrompida a administração. Ao ser solto, demonstrou andar levemente desequilibrado com leves tremores. Às 10:50h, FC 144, FR 28, movimentos respiratórios profundos, jugular saliente pulsando. Às 11:15h apresentou os mesmos sintomas, quando deitou-se em decúbito esternal; tangido insistentemente, não se levantou. Às 11:45h, respiração "repuxando" as narinas. Às 12:00h, pescoço em "S", apático, com a cabeça abaixada. Às 12:03h, início e, às $12: 13 \mathrm{~h}$, término do tratamento. Às $12: 15 \mathrm{~h}$, o animal levantou a cabeça e às $12: 17$ h estava com a respiração normal. Às 12:19h, quando tangido, levantou-se; ficou parado fazendo movimentos de mastigação. Às 13:45h começou a pastar e foi considerado recuperado.

\section{Piptadenia viridiflora}

A ingestão dessa planta induziu, em quatro animais, a um grave quadro de intoxicação com sintomatologia típica de envenenamento cianídrico (vide protocolos). Os dois bovinos (5281 e 5291) submetidos ao tratamento com hiposulfito de sódio se recuperaram rapidamente, enquanto que os dois outros (5267 e 5509) morreram. A necropsia e os exames histopatológicos desses dois ultimos animais não evidenciaram lesões significativas, porém a planta permaneceu reconhecível nas proximidades da cárdia. O bovino (5510) que recebeu a dosagem de $5 \mathrm{~g} / \mathrm{kg}$ não apresentou quaisquer sintomas. Detalhes desses experimentos podem ser encontrados no Quadro 2.

Resumo dos protocolos dos experimentos com $P$. viridiflora:

Bovino 5267. Em 29.11.95, administração da planta entre 17:50h e 18:45h. Em 30.11.95, às 6:30h, de acordo com o vaqueiro, o bezerro estava em estação, com tremores musculares e quase caindo; acabou caindo, ficando em decúbito esternal. Às 9:00h estava em decúbito esternal, apresentava tremores em todo corpo, principalmente na cabeça, nistagmo, fazia movimentos de mastigação, salivação, às vezes apresentava contrações musculares súbitas na parte anterior do corpo. Às 9:00h, T 38,5 ${ }^{\circ}$, FC 168, FR 44, rúmen parado, superfície do corpo fria. Permaneceu em decúbito esternal com a cabeça quase encostada no flanco, com tremores. Morreu às 11:40h. - Achados de necropsia: Epicárdio e endocárdio esquerdos com extensas hemorragias. No rúmen foi possível reconhecer a planta administrada. - Exames histopatológicos (SAP 27910) revelaram endocárdio, miocárdio e epicárdio, com extensas hemorragias, baço com acentuada congestão, fígado com leve vacuolização centrolobular, sistema nervoso central com moderada hiperemia difusa e pequenas hemorragias capilares.

Bovino 5509. Em 5.3.97, administração da planta entre às $11: 10 \mathrm{~h} \mathrm{e}$ 11:40h. Ficou em decúbito esternal. Às 11:57h, quando tangido, levantou-se e apresentou andar levemente desequilibrado, com tremores na região glútea. Às 12:00h evidenciou leves tremores generalizados, instabilidade, quase caindo. Às 12:09h deitou-se rapidamente; fazendo com a cabeça movimentos desordenados; FC 120, FR 48, pescoço em "S". Às 12:15h jugular saliente, pulsando. Não conseguia manter a cabeça erguida, que balançava. Às 12:35h, FC 128, FR 40. Às 12:50h, com respiração cada vez mais dispnéica, com a

Quadro 2. Experimentos em bovinos com as folhas de Piptadenia viridiflora

\begin{tabular}{|c|c|c|c|c|c|c|c|c|c|c|}
\hline $\begin{array}{l}\text { Bov. } \\
\text { no. }\end{array}$ & Folhas & $\begin{array}{c}\text { Data da } \\
\text { coleta }\end{array}$ & Dose $\mathrm{g} / \mathrm{kg}$ & $\begin{array}{l}\text { Data } \\
\text { adm }\end{array}$ & $\begin{array}{l}\text { e hora da } \\
\text { inistração }\end{array}$ & $\begin{array}{l}\text { Início dos } \\
\text { sintomas }\end{array}$ & $\begin{array}{c}\text { Início do } \\
\text { tratamento }\end{array}$ & $\begin{array}{l}\text { Término do } \\
\text { tratamento }\end{array}$ & Recuperação & Morte \\
\hline 5267 & Frescas & 29.11 .95 & 14,1 & 29.11.95 & $17: 50-18: 45 h$ & $\begin{array}{l}30.11 .98 \text {, an- } \\
\text { tes das } 6: 30 \mathrm{~h}\end{array}$ & - & - & - & $\begin{array}{c}30.11 .95 \\
11: 40 \mathrm{~h}\end{array}$ \\
\hline 5510 & “ & 03.03.97 & 5,0 & 03.03.97 & $11: 30-12: 15 \mathrm{~h}$ & - & - & - & - & \\
\hline 5509 & “ & 05.03 .97 & 10,0 & 05.03.97 & $11: 10-11: 40 \mathrm{~h}$ & 11:57h & - & - & - & $15: 15 h$ \\
\hline 5281 & Dessecadas & 16.03 .97 & 4,43 & 17.04 .97 & 09:15-10:05h & $10: 05 h$ & $11: 45 h$ & 11:50h & 14:09h & - \\
\hline 5291 & “ & 01.06 .98 & 7,95 & 16.07 .98 & 09:55-11:20h & $11: 20 h$ & $12: 20$ & 13:00h & $13: 45 h$ & - \\
\hline
\end{tabular}


boca aberta, tremores dos lábios. Às 13:30h ficava cada vez mais inclinado, quase em decúbito lateral. Às 13:40h caiu de lado com a cabeça virada para trás. Às 14:00h, opistótono, ocasionais movimentos de pedalagem, superfície do corpo fria, $T 37,1^{\circ}$. Às $15: 10 \mathrm{~h}$, respiração espaçada, morte às 15:15h. Achados de necropsia: Presença de espuma (edema) na parte inferior da traquéia e nos brônquios. Planta administrada reconhecível no rúmen (região próxima à cárdia). - Exames histopatológicos (SAP 28312/13) revelaram leve congestão esplênica.

Bovino 5281. Em 17.4.97, às 7:50h, T 38,4 $4^{\circ}, \mathrm{FC} 40, \mathrm{FR} 20, \mathrm{Ru} 3 / 2$. Às 9:15h, início da administração. Às 10:05h dificuldades na continuação da administração da planta, que foi suspensa. Quando solto e tangido, $o$ animal apresentou tremores musculares e andar levemente desequilibrado, FC 128, FR 48. Às 10:10h apresentava andar cada vez mais desequilibrado, até que, às 10:25h, o animal ficou em decúbito esternal, com respiração dispnéica, pescoço em " $\mathrm{S}$ ", balançando muito a cabeça. Às 10:57h ficou em decúbito lateral e às vezes mugia. Às $11: 45 \mathrm{~h}$, início e às $11: 50 \mathrm{~h}$, término do tratamento. Às 11:57h, o animal levantou a cabeça. Às 12:05h, FC 88. Às 13:20h ficou em estação. Às 13:45h, quando tangido, andou normalmente. Às 14:09h alimentou-se e foi considerado recuperado.

Bovino 5291. Em 16.7.98, às 8:50h, T 38,2 ${ }^{\circ}$, FC 72, FR 24, Ru 3/2. Às 9:55h, início da administração. Às $11: 20 \mathrm{~h}$, tremores musculares na região escapular. Tangido, apresentou andar levemente desequilibrado, moderado timpanismo. Interrompida a administração da planta. Às 11:40h timpanismo aliviado através de sonda esofagiana. Às 11:45h, T 39,3, FC 144, FR 28. Às 11:50h deitou-se em decúbito esternal com pescoço em "S", respiração dispnéica audível à distância. Até às $12: 20 \mathrm{~h}$ ficou com a cabeça meio inclinada e com o focinho encostado no solo. Às 12:20h, início e às 13:00h, término do tratamento. Às 13:10h, quando tangido, se levantou, com tremores musculares. Às 13:45h começou a se alimentar, recuperado.

\section{Holocalyx glaziovii}

Dos sete bovinos submetidos a experimentação com essa planta, quatro apresentaram sintomas comuns às intoxicação cianídrica, prontamente reversíveis pela administração do tratamento específico(vide protocolos), enquanto três outros não adoeceram. Detalhes sobre esses experimentos encontram-se no Quadro 3.

Resumo dos protocolos dos experimentos com $H$. glaziovii:

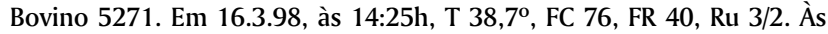
14:30h, início da administração. Às 14:56h começou a ter dificuldades na deglutição. Às 14:57h caiu, ficando em decúbito esternal; interrompida a administração da planta. Às 14:58h, estimulado, levantou, com tremores mus- culares e andar muito incoordenado. Às 15:00h evidenciava muita instabilidade, quase caindo, com dispnéia, FR 40. Até às 15:22h apresentou contrações musculares labiais, instabilidade, dispnéia e agressividade, quando, finalmente deitou-se em decúbito esternal, com dispnéia acentuada e tremores da cabeça. Às 15:32h, inicio e às 15:43h, término do tratamento. Às 15:37 ficou em decúbito lateral. Às 15:46h assumiu o decúbito esternal. Às 15:48h, quando tangido, levantou-se, com leve instabilidade. Às 15:50h, tremores musculares, respiração quase normal. Até às 16:55h ainda com tremores musculares. Às 16:58h comia capim, recuperado.

Bovino 5291. Em 16.3.98, às 14:38, T 38,9 $9^{\circ}$ FC 80 , FR 24, Ru 1/2. Às 15:58h início da administração. Durante a administração da planta, às $16: 33 \mathrm{~h}$, caiu e logo deitou em decúbito lateral. Suspensa a administração. Às 16:37h, estimulado, levantou-se, com muita instabilidade, quase caindo, com tremores musculares. Às 16:42h, FC 160, FR 32. Às 16:52h caiu, ficando em decúbito lateral. Às $16: 53 \mathrm{~h}$, início e às $16: 58 \mathrm{~h}$, término do tratamento. Às 16:59h levantou-se e andou quase normalmente. Às 17:23h começou a comer capim, recuperado.

Bovino 5229. Em 24.7.97, às 10:50h, T 39, $1^{\circ}$, FC 52, FR 32, Ru 3/2. Às 13:42h, início da administração. Às 14:10h começou a comer mais devagar, prolapso da terceira pálpebra. Às 14:12h, FC 80, não deglutia mais; interrompida a administração. Às $14: 18 \mathrm{~h}$ caiu, ficando em posição esternal, fazia movimentos de mastigação. Às 14:23h, com respiração abdominal, pescoço levemente em "S", tremores musculares, FC 104, FR 28. Às 14:25h levantouse, com muita instabilidade, quase não conseguindo ficar em pé e com tremores musculares generalizados. Às $14: 40 \mathrm{~h}$, com prolapso da terceira pálpebra. Às 14:45h deitou-se, FC 120 . Às 14:50h, início e às 15:02h, término do tratamento, já com respiração quase normal. Às 15:04h FC 84, tangido, levantou-se, com andar um pouco desequilibrado. Às 15:16h estava pastando, recuperado.

Bovino 5228. Em 30.5.97, às $14: 40 h, T 39,0^{\circ}$, FC 76, FR 24, Ru 3/2. Às 14:45h, início da administração. Às $15: 18 \mathrm{~h}$ caiu, ficando em decúbito esternal; interrompida a administração, prolapso da terceira pálpebra, com nistagmo e movimentos de mastigação. Às 15:22h, FC 100, FR 24. Às 15:23h FC 148, fazia movimentos pendulares com a cabeça. Às 15:25h FR 32. Às 15:32h início, e às 15:42h, término do tratamento. Às 15:50h, FC 80, FR 20. Às 15:55, quando tangido, levantou-se logo; andar lento. Às 16:04h ingeriu capim, recuperado.

\section{Manihot glaziovii}

Dos quatro animais que receberam essa planta, dois evidenciaram sintomatologia característica de intoxicação cianídrica (vide protocolos), prontamente reversível após o tratamento com hipossulfito de sódio. Detalhes desses experimentos podem ser encontrados no Quadro 4.

Quadro 3. Experimentos em bovinos com as folhas de Holocalyx glaziovii

\begin{tabular}{|c|c|c|c|c|c|c|c|c|c|}
\hline $\begin{array}{l}\text { Bov. } \\
\text { no. }\end{array}$ & Folhas & $\begin{array}{c}\text { Data da } \\
\text { coleta }\end{array}$ & Dose $\mathrm{g} / \mathrm{kg}$ & \multicolumn{2}{|c|}{$\begin{array}{l}\text { Data e hora da } \\
\text { administração }\end{array}$} & $\begin{array}{r}\text { Início dos } \\
\text { sintomas } \\
\end{array}$ & $\begin{array}{l}\text { Início do } \\
\text { tratameto }\end{array}$ & $\begin{array}{l}\text { Término do } \\
\text { tratamento }\end{array}$ & Recuperação \\
\hline 5271 & Frescas & 16.03 .98 & 3,5 & 16.03 .98 & $14: 30-14: 57 \mathrm{~h}$ & 14:57h & $15: 32 \mathrm{~h}$ & 15:43h & $16: 58 h$ \\
\hline 5291 & “ & 16.03 .98 & 3,71 & 16.03 .98 & 15:58-16:33h & $16: 33 h$ & 16:53h & $16: 58 h$ & $17: 23 \mathrm{~h}$ \\
\hline 5228 & Dessecadas & 28.04 .97 & 1,065 & 30.05 .97 & $14: 45-15: 18 h$ & $15: 18 \mathrm{~h}$ & $15: 32 \mathrm{~h}$ & $15: 42 \mathrm{~h}$ & $16: 04 h$ \\
\hline 5227 & “ & 28.04 .97 & 1,5 & 02.07 .97 & 09:20-11:00h & - & - & - & - \\
\hline 5229 & “ & 28.04 .97 & 2,73 & 24.07.97 & $13: 42-14: 12 \mathrm{~h}$ & $14: 12 \mathrm{~h}$ & $14: 50 \mathrm{~h}$ & $15: 02 \mathrm{~h}$ & $15: 16 h$ \\
\hline 5290 & “ & 28.04 .97 & 3,0 & 04.03 .98 & 10:07-11:05h & - & - & - & - \\
\hline 5288 & “ & 28.04 .97 & 7,5 & 04.03 .98 & $13: 25-16: 40 \mathrm{~h}$ & - & - & - & - \\
\hline
\end{tabular}

Quadro 4. Experimentos em bovinos com as folhas frescas de Manihot glaziovii

\begin{tabular}{|c|c|c|c|c|c|c|c|c|}
\hline $\begin{array}{l}\text { Bov. } \\
\text { no. }\end{array}$ & $\begin{array}{l}\text { Folhas } \\
\text { com talos }\end{array}$ & $\begin{array}{c}\text { Data da } \\
\text { coleta }\end{array}$ & Dose $\mathrm{g} / \mathrm{kg}$ & $\begin{array}{c}\text { Data e hora da } \\
\text { administração }\end{array}$ & $\begin{array}{l}\text { Início dos } \\
\text { sintomas } \\
\end{array}$ & $\begin{array}{c}\text { Início do } \\
\text { tratamento }\end{array}$ & $\begin{array}{l}\text { Término do } \\
\text { tratamento }\end{array}$ & Recuperação \\
\hline 5296 & Frescas & 31.03 .98 & 5,2 & $10: 40-11: 49 \mathrm{~h}$ & $11: 49 \mathrm{~h}$ & - & - & $12: 05 h$ \\
\hline 5532 & , & 31.03 .98 & 10,0 & $14: 50-15: 50 \mathrm{~h}$ & $16: 15 h$ & $16: 15 h$ & $16: 20 h$ & $16: 50 h$ \\
\hline 5536 & 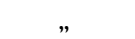 & 15.04 .98 & 5,65 & $10: 40-12: 02 \mathrm{~h}$ & $12: 02 \mathrm{~h}$ & - & - & $12: 40 \mathrm{~h}$ \\
\hline 5534 & 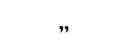 & 15.04 .98 & 7,1 & $14: 45-15: 35 h$ & $15: 35 h$ & $15: 42 \mathrm{~h}$ & $15: 55 h$ & $16: 10 \mathrm{~h}$ \\
\hline
\end{tabular}


Resumo dos protocolos dos experimentos com M. glaziovii: Bovino 5296. Em 31.03.98, às 10:40h, início da administração. Às 11:49h foi interrompida a administração, pois o animal não mais mastigava, nem engolia. Apresentou discreta instabilidade e leve taquipnéia (FR 28). Às 12:05 começou a pastar, recuperado.

Bovino 5532. Em 31.03.98, às 14:30h, T 38, $4^{\circ}, \mathrm{FC} 60, \mathrm{FR} 20$, Ru 3/2. Às 14:50h, início da administração. Às $15: 50 \mathrm{~h}$ caiu repentinamente e não se levantou, mesmo sendo bastante estimulado; interrompida a administração da planta. Às 15:55h, FC 116, FR 36, respiração profunda. Às 16:05h, quando tangido, levantou-se, com andar bastante desequilibrado; em estação, com grande instabilidade. Às 16:08h deitou-se rapidamente, FR 40, dispnéica. Às 16:11h levantou-se, ficando em estação, com muita instabilidade e tremores musculares. Às $16: 15 \mathrm{~h}$ deitou-se novamente; início e às $16: 20 \mathrm{~h}$, término do tratamento. Às 16:22h, quando estimulado, levantou-se rapidamente, FR 16. Às 16:35h FC 84. Às 16:50h estava pastando, recuperado.

Bovino 5536. Em 15.04.98, às 10:40h, início da administração. Às 12:02h foi interrompida a administração, pois o animal apesar de mastigar muito a planta, não mais a deglutia. Apresentou tremores musculares na região da escápula. Tangido, apresentou andar desequilibrado, FC 128 e FR 28, respiração ofegante. Estes sintomas, de intensidade moderada, foram progressivamente diminuindo em intensidade $\mathrm{e}$, às $12: 40 \mathrm{~h}$, $\mathrm{o}$ animal começou a pastar, recuperado.

Bovino 5534. Em 15.04.98, às 14:35h, T 39, $0^{\circ}, \mathrm{FC} 56, \mathrm{FR} 20$, Ru 3/2. Às 14:45h, início da administração. Às 15:25h, o animal começou a apresentar dificuldade em engolir a planta, mastigava muito, salivando, sem deglutir. Às 15:35h foi interrompida a administração e $o$ animal foi tangido para o piquete, apresentando andar muito desequilibrado, com tremores em todo corpo; quando em estação, demonstrou muita instabilidade. Às 15:38h ficou em decúbito esternal. Âs $15: 40 \mathrm{~h}$, pescoço em " $\mathrm{S}$ ", a cabeça balançando em sentido horizontal, com respiração ofegante, FR 60. Às 15:42h, início e às 15:55h, fim do tratamento. Levantou-se logo. Às 16:10h começou a comer capim, recuperado.

Testes com papel picro-sódico

Os principais dados sobre o teste do papel picro-sódico com as quatro plantas constam no Quadro 5.

\section{DISCUSSÃO E CONCLUSÕES}

Em relação a Piptadenia macrocarpa, verificou-se que as folhas frescas recém-coletadas em outubro, quando em fase de brotação, são mais tóxicas que em março, quando maduras. Também ficou confirmado que as folhas dessecadas continuam tóxicas, mas que, com o tempo, vão perdendo em toxidez (em questão de meses). Assim, numa série de experimentos, após pouco mais de 4 meses, não se conseguiu causar sequer leves sintomas, apesar das grandes quantidades das folhas administradas. Em outro experimento a planta ainda continuou muito tóxica quase 3 meses após a coleta.

$P$. viridiflora revelou-se tóxica para bovinos, causando quadro clínico-patológico semelhante ao observado na intoxicação por $P$. macrocarpa. Apesar do pequeno número de experimentos com as folhas frescas, pode-se admitir que a dose letal é semelhante. Verificou-se que as folhas dessecadas continuam tóxicas, porém não foi possível averiguar se com o tempo vão perdendo em toxidez.

Verificou-se que as folhas dessecadas de Holocalyx glaziovii perdem em toxidez com o passar do tempo. Dez meses após sua coleta, a administração de quantidades correspondentes a 5 doses letais, não causaram quaisquer sintomas de intoxicação.

Não foi possível, a partir de determinado momento, con- tinuar com a administração da planta a dois bovinos que receberiam quantidade das folhas de Manihot glaziovii até adoecerem gravemente, para então serem submetidos ao tratamento por hipossulfito,. O Bovino 5296 tinha ingerido 5,2 g/ $\mathrm{kg}$ e o Bovino $5536,5,65 \mathrm{~g} / \mathrm{kg}$ das folhas de $M$. glaziovii. Além desta manifestação de não mais deglutirem a planta, mostraram, respectivamente, leves e moderados sintomas de intoxicação. Não lhes foi aplicado medicação; se recuperaram espontaneamente.

No que diz respeito à sintomatologia, observou-se que a incapacidade de deglutição constitui-se, quase sempre, no primeiro sintoma da intoxicação cianídrica.

$\mathrm{O}$ tratamento à base de hipossulfito de sódio, aplicado a bovinos intoxicados gravemente pelas quatro plantas cianogênicas, sempre foi capaz de promover a imediata recuperação dos animais. Embora, em intoxicações espontâneas haja pouco tempo hábil para aplicação, o tratamento é de grande valia no reconhecimento de plantas cianogênicas.

\section{Teste do papel picro-sódico}

Dadas as variações de tempo observadas nos experimentos com as diversas plantas, pode-se concluir que o teste do papel picro-sódico tem valor apenas relativo na avaliação das concentrações de glicosídeos cianogênicos em material vegetal. De fato, as reações positivas observadas no teste feito com as folhas de Manihot glaziovii e de Holocalyx glaziovii foram sempre muito rápidas (dentro de 5 minutos), enquanto que com as de Piptadenia macrocarpa e de Piptadenia viridiflora, as reações sempre foram mais lentas (dentro de 15 minutos e de 10 a 30 minutos, respectivamente) para a brotação e ainda mais retardadas para as folhas maduras.

De uma maneira geral, as reações mais lentas ao teste do papel picro-sódico, além de estarem correlacionadas diretamente com os quadros clínicos de evolução mais protraída, também podem indicar um menor grau de toxidez.

A variação nessas reações pode ser atribuída a diversos fatores. Everist (1974) lembra que certos glicosídeos se desintegram com facilidade, enquanto outros se mantêm estáveis; em algumas plantas, a liberação de $\mathrm{HCN}$ é mais rápida do que em outras, seja pela natureza dos próprios glicosídeos, seja pelo tipo e quantidade de enzimas disponíveis para a hidrólise.

Observou-se que os resultados do teste do papel picrosódico, realizado com as folhas dessecadas, apareciam ainda mais lentamente, porém as plantas permaneciam capazes de induzir a intoxicação letal. Aplin (1976) afirma que as plantas perdem o HCN quando cortadas, dessecadas ou submetidas a processo de volatilização e também que o feno preparado a partir de plantação potencialmente perigosa será, quando bem seco, seguro para a alimentação dos animais. Nosso resultados estão mais de acordo com as observações de Kingsbury (1964), segundo as quais o feno fresco preparado com algumas plantas pode ser perigoso, embora, com o passar do tempo não haja maiores riscos na ingestão desse feno, provavelmente pela volatilização do $\mathrm{HCN}$.

Também a esse respeito, Van der Walt (1944) informa que a quantidade de HCN liberado por Andropogon sorghum é 
Quadro 5. Reações ao teste do papel picro-sódico das folhas de Piptadenia macrocarpa, P. viridiflora, Holocalyx glaziovii e Manihot glaziovii

\begin{tabular}{|c|c|c|c|c|}
\hline \multicolumn{5}{|c|}{ Piptadenia macrocarpa } \\
\hline $\begin{array}{l}\text { Tempo de reação } \\
\text { (em minutos) }\end{array}$ & $\begin{array}{l}\text { Folhas frescas col., admi- } \\
\text { nistradas em 17.03.98 } \\
\text { (Bov. 5288, 5290) e tes- } \\
\text { tadas em 17.03.98 }\end{array}$ & $\begin{array}{l}\text { Folhas frescas col., admi- } \\
\text { nistradas em 16.10.98 } \\
\text { (Bov. 5287, 5292) e tes- } \\
\text { tadas em 20.10.98 }\end{array}$ & $\begin{array}{l}\text { Folhas dessecadas, col. } \\
\text { em } 28.10 .97 \text {, administra- } \\
\text { das em 05.03.98 (Bov. } \\
5292,5287 \text { ) e testadas } \\
\text { em } 05.03 .98\end{array}$ & $\begin{array}{l}\text { Folhas dessecadas, col. } \\
\text { em } 16.10 .98 \text {, administra- } \\
\text { das em 13.01.99 (Bov. } \\
5296 \text { ) e testadas } \\
\text { em 22.01.99 }\end{array}$ \\
\hline 5 & -a & + & & \\
\hline 10 & - & ++ & & - \\
\hline 15 & - & +++ & - & - \\
\hline 20 & $(+)$ & & & + \\
\hline 30 & & & & $+(+)$ \\
\hline 45 & + & & $(+)$ & ++ \\
\hline 60 & & & + & +++ \\
\hline
\end{tabular}

\begin{tabular}{|c|c|c|c|c|}
\hline \multicolumn{5}{|c|}{ Piptadenia viridiflora } \\
\hline $\begin{array}{l}\text { Tempo de reação } \\
\text { (em minutos) }\end{array}$ & $\begin{array}{c}\text { Folhas frescas (brotação) } \\
\text { col. e administradas em } \\
\text { 03.03.97 (Bov. 5510), } \\
\text { testadas em 03.03.97 }\end{array}$ & $\begin{array}{c}\text { Folhas frescas (brotação) } \\
\text { col. e administradas em } \\
05.03 .97 \text { (Bov. 5509) } \\
\text { testadas em 05.03.97 }\end{array}$ & $\begin{array}{l}\text { Folhas frescas (maduras) } \\
\text { col. em } 05.03 .97 \text {, (não sub- } \\
\text { metidas a experimenta- } \\
\text { ção), testadas em } 05.03 .97\end{array}$ & $\begin{array}{c}\text { Folhas dessecadas, col. } \\
\text { em 01.06..98, administra- } \\
\text { das em 15.07.98 (Bov. } \\
\text { 5291), testadas em 16.07.98 }\end{array}$ \\
\hline
\end{tabular}

$\begin{array}{ccccc}5 & + & (+) & - & - \\ 10 & +++ & + & - & - \\ 15 & & +(+) & (+) & - \\ 20 & & ++ & ++ & +(+) \\ 30 & & ++ & ++ & ++ \\ 45 & & ++\end{array}$

\section{Holocalyx glaziovii}

\begin{tabular}{|c|c|c|c|}
\hline $\begin{array}{l}\text { Tempo de reação } \\
\text { (em minutos) }\end{array}$ & $\begin{array}{l}\text { Folhas frescas col. e admi- } \\
\text { nistradas em 16.03.98 } \\
\text { (Bov. 5271, 5291), tes- } \\
\text { tadas em 16.03.98 }\end{array}$ & $\begin{array}{l}\text { Folhas dessecadas, col. } \\
\text { em 28.04.97, administra- } \\
\text { das em 24.07.98 (Bov. } \\
\text { 5229), e testadas } \\
\text { em 24.07.97 }\end{array}$ & $\begin{array}{l}\text { Folhas dessecadas, col. } \\
\text { em } 28.04 .97 \text {, administra- } \\
\text { das em } 04.03 .98 \text { (Bov. } \\
5290,5288 \text { ), e testadas } \\
\text { em } 04.03 .98\end{array}$ \\
\hline 5 & ++ & $+(+)$ & - \\
\hline 10 & +++ & +++ & \\
\hline 15 & & & \\
\hline 45 & & & + \\
\hline 120 & & & ++ \\
\hline
\end{tabular}

Manihot glaziovii

\begin{tabular}{ccc}
$\begin{array}{c}\text { Tempo de reação } \\
\text { (em minutos) }\end{array}$ & $\begin{array}{c}\text { Folhas frescas col. e admi- } \\
\text { nistradas em 31.03.98 } \\
\text { (Bov. 5296, 5532), e tes- } \\
\text { tadas em 15.04.98 }\end{array}$ & $\begin{array}{c}\text { Folhas frescas col. e admi- } \\
\text { nistradas em 15.04.98 } \\
\text { (Bov. 5536, 5534), tes- } \\
\text { tadas em 15.04.98 }\end{array}$ \\
\hline
\end{tabular}

$\begin{array}{ccc}1 & & (+) \\ 2 & + & +(+) \\ 3 & ++ & ++(+) \\ & +++ & +++\end{array}$

\footnotetext{
a +++ Reação acentuada, ++ moderada, + leve, $(+)$ discreta, - sem reação.
}

menor quando o processo de dessecagem é rápido e que "Sudan grass" (Sorghum sp.) dessecado em forno perde um pouco de HCN, porém mais HCN é perdido quando esse pro- cesso é feito ao sol; quando dessecado à sombra, o HCN é todo ou quase totalmente eliminado. Conn (1979) se refere a presença de glicosídeos cianogênicos em material herbariza- 
do, mas chama a atenção para o fato de que o processo de dessecagem pode inativar enzimas originalmente presentes.

Conn (1979) lembra que o teste do papel picro-sódico não funciona se o tecido vegetal não contém a enzima para a hidrólise do glicosídeo cianogênico. De acordo com Coop \& Blakley (1949), este fato não deve influenciar muito a toxidez destas plantas em relação aos bovinos (frescas ou dessecadas), pois sabe-se que as bactérias ruminais podem hidrolizar com rapidez os glicosídeos cianogênicos.

Agradecimentos.- Agradecemos ao Dr. Marcus Nadruz, Jardim Botânico do Rio de Janeiro, pela identificação de Piptadenia viridiflora.

\section{REFERÊNCIAS}

Aplin T.E.H. 1976. Cyanogenetic plants of Western Australia. Bulletin 3967, Western Australian Department of Agriculture. 14 p.

Armién A.G., Peixoto P.V., Döbereiner J. \& Tokarnia C.H. 1995. Intoxicação experimental por Holocalyx glaziovii (Leg. Mimosoideae) em bovinos. Pesq.Vet. Bras. 15(4):89-92.

Radostits O.M., Blood D.C. \& Gay C.C. 1994. Veterinary Medicine. 8th ed. Baillière Tindall, London, p.1535.

Burrows G.E. 1981. Cyanid intoxication in sheep: Therapeutics. Vet. Hum. Toxicol. 23(1):22-28.

Conn E.E. 1979. Cyanids and cyanogenic glycosides, p. 387-412. In: Rosenthal G.A. \& Janzen D.H. (ed.) Herbivores: Their Interaction with Secondary Plant Metabolites. Academic Press, New York.

Coop I.E. \& Blakley R.L. 1949. The metabolism and toxicity of cyanides and cyanogenetic glucosides in sheep. 1. Activity in the rumen. N.Z.J.Sci.Technol., Sect. A, 30:277-291.

Everist S.L. 1974. Poisonous Plants of Australia. Angus and Robertson, Sidney.

Henrici M. 1926. Preliminary report upon the occurrence of hydrocyanic acid in the grasses of Bechuanaland. 11th and 12th Rep. Director Vet. Educ. Res., Part I, Pretoria, p. 495-498.

Tokarnia C.H., Döbereiner J. \& Peixoto P.V. 1994. Aspectos clínico-patológicos complementares da intoxicação por algumas plantas tóxicas brasileiras. Pesq. Vet. Bras. 14(4):111-122. 